http://dx.doi.org/10.18675/1981-8106.vol26.n52.p264-278

\title{
Textos relacionados à Educação em Ciências: caracterizando formações discursivas de livros didáticos e da divulgação científica
}

\author{
Texts related to Science Education: featuring discursive formations of \\ textbooks and popular Science
}

\section{Textos relacionados a la Educación en Ciencias: caracterizando formaciones discursivas de libros didácticos y de la divulgación científica}

\author{
Tatiana Galieta' \\ "Universidade do Estado do Rio de Janeiro, Rio de Janeiro - Brasil. E-mail: tatigalieta@gmail.com
}

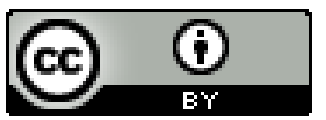

Educação: teoria e prática, Rio Claro, SP, Brasil - eISSN: 1981-8106

Está licenciada sob Licença Creative Common

\section{Resumo}

$\mathrm{Na}$ área de Educação em Ciências, a Análise de Discurso de linha francesa tem sido utilizada como referencial teórico e metodológico em pesquisas sobre linguagem. Dentre essas, percebemos que o foco sobre textos escritos está geralmente relacionado ao seu funcionamento em situações didáticas na sala de aula de ciências. Buscando contribuir para a ampliação do escopo de pesquisas filiadas aos estudos do discurso, é apresentado um exercício de análise de textos de um livro didático de ciências e de uma revista de divulgação científica utilizando a Análise de Discurso como base teórica para a elaboração de um dispositivo analítico que se divide em três etapas: seleção do corpus, descrição do corpus e interpretação do objeto discursivo buscando caracterizar dois gêneros textuais específicos relacionados a diferentes formações discursivas. Os resultados mostram que os textos do livro didático e de divulgação científica são atravessados por diferentes formações discursivas que se remetem aos discursos da ciência, do cotidiano e do ensino de ciências.

Palavras-chave: Educação em Ciências. Análise de Discurso. Livro didático. Texto de divulgação científica. Formações discursivas. 
In the area of Science Education, the French Discourse Analysis has been used as a theoretical and methodological framework for research on language. Among these, we realize that the focus on written texts is usually related to its operation in teaching situations in classroom science. Seeking to contribute to expanding the scope of research affiliated to discourse studies, we present an analysis exercise texts of a textbook and a popular science journal using Discourse Analysis. This approach was used as a theoretical basis for the development of an analytical device divided into three stages: selection of the corpus, the corpus description, and interpretation of the discursive object seeking to characterize two specific textual genres related to different discursive formations. The results show that different discursive formations traverse the texts of textbooks and scientific publishing, which is supposed to refer to the discourses of science, of daily life and science education.

Keywords: Science Education. Discourse Analysis. Textbook. Popular science text. Discoursive formations.

\section{Resumen}

En el área de Educación en Ciencias, el Análisis del Discurso de línea francesa se ha utilizado como referencial teórico y metodológico en investigaciones sobre lenguaje. Entre estas, percibimos que el foco sobre textos escritos está generalmente relacionado a su funcionamiento en situaciones didácticas en la sala de clase de ciencias. Buscando contribuir para la ampliación del objetivo de investigaciones filiadas a los estudios del discurso, se presenta un ejercicio de análisis de textos de un libro didáctico de ciencias y de una revista de divulgación científica utilizando el Análisis del Discurso como base teórica para la elaboración de un dispositivo analítico que se divide en tres etapas: selección del corpus, descripción del corpus e interpretación del objeto discursivo buscando caracterizar dos géneros textuales específicos relacionados a diferentes formaciones discursivas. Los resultados muestran que los textos del libro didáctico y de divulgación científica son permeados por diferentes formaciones discursivas que se remiten a los discursos de la ciencia, del cotidiano y de la enseñanza de ciencias.

Palabras clave: Educación en Ciencias. Análisis de Discurso. Libro didáctico. Texto de divulgación científica. Formaciones discursivas.

\section{Introdução}

A Análise de Discurso de linha francesa (AD), pautada nas obras de Michel Pêcheux e Eni Orlandi, tem sido utilizada (e recontextualizada) tanto como referencial teórico quanto metodológico em pesquisas sobre linguagem na área de Educação em Ciências. Os objetos de estudo dessas pesquisas são os mais diversos, no entanto, destacam-se as análises dos discursos de sujeitos envolvidos no contexto de entrevistas, interações discursivas na sala de aula de ciências e também do funcionamento de textos em aulas de ciências (NICOLLI et al., 
2011; PINHÃO e MARTINS, 2009; SOUZA et al., 2014). Por outro lado, análises de elementos textuais que constroem a composição de um discurso escrito materializado em distintos gêneros, apoiada em um quadro teórico-metodológico da AD, ainda são escassas.

Os estudos linguísticos que têm como objeto textos escritos relacionados ao ensino de ciências (predominantemente livros didáticos e textos de divulgação científica, mas também originais de cientistas e livros paradidáticos, entre outros) têm se utilizado de metodologias diversas apoiadas em referenciais teóricos derivados de diferentes autores. Observamos na literatura que análises de livros didáticos de ciências pautam-se em teorias propriamente linguísticas (como as de Bakhtin, Halliday, Lemke e VanDijk) ou discursivas (como, por exemplo, a análise crítica de discurso de Fairclough) (exemplos em: LIMA et al., 2011; MOREIRA, 2012; PEREIRA e TERRAZAN, 2011; PINHÃO e MARTINS, 2012). A AD, apesar de servir como terreno teórico para pesquisas que têm textos como seus objetos de estudo, tem sido pouco explorada como dispositivo analítico dos mesmos.

Nesse sentido, o presente artigo realiza um exercício de análise de textos de um livro didático de ciências e de uma revista de divulgação científica utilizando a AD como base para a elaboração de categorias analíticas que buscam caracterizar esses dois gêneros textuais específicos como estando relacionados a diferentes formações discursivas. Para tanto, partimos de três pressupostos: (i) a linguagem é considerada em seu funcionamento, enquanto discurso, constituindo-se materialmente em diferentes gêneros textuais; (ii) os textos, ao mesmo tempo em que constituem, são constituídos pelas formações discursivas às quais eles pertencem; (iii) os textos são atravessados por diferentes discursos e é essa interdiscursividade que acaba por dar "identidade" ao gênero textual. As bases teóricas que subsidiam esses pressupostos e sobre as quais elaboramos o dispositivo analítico aqui proposto são expostas na próxima seção.

\section{Análise de Discurso: considerações teóricas}

O paradigma estruturalista, que tem seu auge em meados da última década do século XX, propunha, dentro da Linguística, a análise da língua enquanto estrutura formal submetida à rigorosidade do método científico, o qual considerava por completo a exclusão do sujeito. Assim, "importava normalizar o sujeito, já que era visto como o elemento suscetível de perturbar a análise do objeto científico, que deveria corresponder a uma língua objetivada, padronizada" (FERREIRA, 2003, p. 40). Com a publicação, em 1969, de Análise Automática do Discurso, Pêcheux confronta o excessivo formalismo linguístico a partir de uma releitura dos conceitos de língua, historicidade e sujeito. Esse autor traz, então, contribuições do materialismo histórico e da psicanálise para reformular e recolocar o sujeito como centro do processo discursivo, atribuindo particular importância à sua descentralidade, inconsciência e ideologia. Muda-se, portanto, a própria concepção do que é a linguagem e, por conseguinte, do que é a língua, chegando-se a uma reformulação do objeto de estudo que agora é o discurso. 
A Análise de Discurso fundada por Pêcheux estabelece um objeto diferente daquele instaurado pela Linguística tradicional, porque trata dos processos de constituição do fenômeno linguístico e não meramente do seu produto. Ao serem considerados tais processos, a linguagem passa a se caracterizar como transformadora, como interação, uma vez que ela reside na relação necessária entre homem e realidade natural e social (ORLANDI, 1993). A linguagem é assumida como um trabalho simbólico, como produção, deslocando a importância dada à sua função referencial passando a valorizar sua função ideológica.

Desta forma, a linguagem deixa de ser vista apenas como um "meio de comunicação", enquanto instrumento utilizado com o objetivo de comunicar e transmitir informações, passando a ser considerada como mediação, como processo de produção de sentidos, ou seja, em seu funcionamento enquanto discurso. Este, por sua vez, dispõe de formas de apropriação pelo indivíduo falante, do universo da língua, implicando a participação do sujeito na linguagem (ORLANDI, 1983). As formas de apropriação da linguagem estão relacionadas às práticas sociais nas quais o sujeito participa de modo que ele "sabe" o que pode e deve dizer ou deixar de dizer em uma dada conjuntura. "O dizer está pois ligado às suas condições de produção. Há um vínculo constitutivo ligando o dizer com sua exterioridade" (ORLANDI, 2005). Estas “diferentes regiões do dizível para os sujeitos” são nomeadas por Pêcheux (1990) de formações discursivas.

Segundo Orlandi (2002), a noção de formação discursiva é básica na AD, "pois permite compreender o processo de produção dos sentidos, a sua relação com a ideologia e também dá ao analista a possibilidade de estabelecer regularidades no funcionamento do discurso" (p. 43). Por causa da propriedade fundamental de todo discurso, de se constituir no/pelo diálogo com outros discursos (interdiscursividade), é que se entende que toda formação discursiva é heterogênea e atravessada por outras formações discursivas. Os sentidos dependem de relações constituídas nas/pelas formações discursivas que possuem fronteiras fluidas e configuram-se e reconfiguram-se continuamente em suas relações (ORLANDI, 2002).

Ao compreendermos que o discurso possui uma materialidade textual e que o texto se relaciona a uma dada formação discursiva, podemos dirigir nosso olhar analítico sobre o texto buscando remetê-lo aos diferentes discursos que o atravessam e o constituem como um gênero específico. Em acordo com Martins (2006, p. 20), "o texto nos interessa não como objeto final, mas como algo que nos permite ter acesso ao discurso". Buscamos, assim, localizar marcas textuais relacionadas a diferentes discursos que, ao serem selecionadas pelo sujeito/autor do texto, dão a este uma identidade própria, permitindo-lhe estar inscrito em uma dada formação discursiva.

\section{Análise de Discurso: um dispositivo analítico de textos escritos}

Conforme comentamos anteriormente, a AD tem sido pouco explorada enquanto método analítico de textos escritos, uma vez que há uma tradição de análises de discursos orais. No caso específico da área de Educação em Ciências, pesquisas que investem na 
compreensão do funcionamento de textos em aulas de ciências têm sido predominantes (ALMEIDA et al., 2001; SILVA e ALMEIDA, 2005). Encontramos, ainda, estudos que aprofundam aspectos relacionados às histórias de leitura de professores em atuação ou em formação inicial (ANDRADE e MARTINS, 2006; CASSIANI de SOUZA e GALIETANASCIMENTO, 2006; NICOLLI e CASSIANI, 2012) e aos processos interpretativos de leitura e escrita de textos em aulas de ciências (ALMEIDA et al., 2008; GIRALDI, 2012). Consideramos relevante destacar que em várias pesquisas que têm na $\mathrm{AD}$ seu referencial teórico-metodológico há uma multiplicidade de objetos de análise que eventualmente se alternam e que se complementam em um contexto mais amplo da investigação.

Notamos, então, que análises de textos escritos relacionados ao ensino de ciências sob uma perspectiva não apenas teórica, mas também metodológica, da $\mathrm{AD}$ são ainda escassas na literatura da área. Destacamos dois estudos que analisam textos didáticos baseados em dois constructos teóricos da $\mathrm{AD}$, a saber: as condições de produção e o silêncio. No primeiro deles, Cassiani de Souza (2006) analisa as condições de produção de módulos didáticos destinados à Educação de Jovens e Adultos considerando aspectos históricos que envolveram a produção dos textos mas que, de acordo com suas conclusões, não necessariamente determinam as interpretações de seus leitores. No segundo, Giraldi (2007) analisa os discursos presentes em livros didáticos de Biologia sobre o tema transgênicos, observando não apenas o que é dito, mas também o que se encontra silenciado nos textos. Assim, a autora aponta que, ao selecionarem seus dizeres, os autores apagam outras possibilidades de produção de sentidos vinculando-se a determinada formação discursiva. Esses estudos são exemplos de como proceder a análise de textos baseados na $\mathrm{AD}$, porém, buscamos neste trabalho desenvolver um dispositivo analítico que atenda a objetivos específicos.

Para tanto, baseados nas considerações de Orlandi (2002), traçamos as etapas que constituirão o dispositivo analítico que será utilizado em nosso exercício de análise apresentado na próxima seção. São elas:

$1^{\text {a }}$ etapa: Constituição do corpus. A delimitação do corpus segue critérios teóricos e não empíricos (positivistas). O corpus é composto por textos que são as unidades de análise. A função do analista consiste em remeter o texto imediatamente a um discurso, de modo a explicitar "suas regularidades pela sua referência a uma ou outra formação discursiva que, por sua vez, ganha sentido porque deriva de um jogo definido pela formação ideológica dominante naquela conjuntura" (ORLANDI, 2002, p. 63). O corpus resulta de uma construção do próprio analista, ou seja, ele é delimitado de acordo com o objetivo do analista, a natureza do material e a pergunta da pesquisa. Esta seleção definirá um corpus bruto, ou seja, "o material de linguagem bruto coletado, tal como existe". (ORLANDI, op. cit., p. 65).

$2^{\text {a }}$ etapa: Descrição do corpus. Segundo Orlandi (2002), o dispositivo analítico "deve explicitar os gestos de interpretação que se ligam aos processos de identificação dos sujeitos, suas filiações de sentidos (...). Nessa empreitada, descrição e interpretação se interrelacionam" (p. 60). É o dispositivo teórico que permite ao analista não ter a ilusão de que, na etapa descritiva do corpus, ele não está envolvido na interpretação. Porém, é a base teórica que permite ao analista atravessar "o efeito de transparência da linguagem, da literalidade do 
sentido e da onipotência do sujeito" (ORLANDI, 2002, p. 61). O analista de discurso trabalha no entremeio da descrição com a interpretação. Com a descrição, o corpus bruto começa a tornar-se objeto discursivo, pois o material já recebeu um tratamento de análise superficial dando início ao processo de "de-superficialização". Nesse processo realiza-se a análise da materialidade linguística: o como se diz, o quem diz e em que circunstância é dito. Consideramos aqui que a etapa descritiva permite a identificação de características textuais mais específicas a partir das quais o analista poderá adentrar ao espaço interpretativo, propriamente dito, buscando relações com as formações discursivas que "selecionam" o que foi dito e como foi dito.

$3^{\text {a }}$ etapa: Interpretação do objeto discursivo. Da mesma forma como nas etapas anteriores, na interpretação o analista deve ter como ponto de partida e de chegada sua teoria. É a partir dela que ele pode definir o que, no objeto discursivo, interessa ser analisado de acordo com sua pergunta e seu objetivo. No caso específico de textos escritos relacionados à Ciência, interessa-nos os constructos teóricos da AD de condições de produção e interdiscursividade. Sendo assim, exploraremos as relações de sentidos (considerando que "um dizer tem relação com outros dizeres realizados, imaginados ou possíveis", buscamos na intertextualidade a relação que existe entre um discurso e outros); as relações de força (estabelecidas entre quem escreve e seu leitor já que "o lugar a partir do qual fala o sujeito é constitutivo do que ele diz"); e o mecanismo de antecipação (o autor ao colocar-se no lugar do leitor antecipa-se ao seu interlocutor quanto aos sentidos que suas palavras podem produzir; "esse mecanismo regula a argumentação, de tal forma que o sujeito dirá de um modo, ou de outro, segundo o efeito que pensa produzir em seu ouvinte") (ORLANDI, 2002, p. 39).

A partir do dispositivo analítico proposto acima, realizamos um exercício de análise de textos relacionados ao discurso científico em diferentes contextos: o de ensino formal (livro didático) e não formal (revista de divulgação científica) apresentado na seção a seguir.

\section{Exercício de análise: a "adrenalina" em textos do livro didático e de divulgação científica}

\subsection{1 ${ }^{\text {a }}$ Etapa: Constituição do corpus}

Estudos anteriores caracterizam textos de livros didáticos e textos de divulgação científica como gêneros textuais distintos que materializam gêneros discursivos que possuem características estilísticas, composicionais e temáticas específicas (BRAGA e MORTIMER, 2003; GALIETA-NASCIMENTO, 2005). Partindo dessa premissa teórica, selecionamos dois textos que consideramos estarem circunscritos em duas formações discursivas (livro didático de ciências e revista de divulgação científica), mas que guardam relações entre elas uma vez que ambas estão relacionadas ao discurso científico. Esta seleção está em acordo com nosso objetivo - a caracterização das formações discursivas por meio da identificação de marcas textuais que dão identidade aos gêneros em questão - e nossa pergunta, a saber: quais 
discursos atravessam os textos que se encontram circunscritos em duas formações discursivas distintas ao tratarem de um mesmo conteúdo científico?

O conteúdo escolhido foi "adrenalina”. Essa opção deu-se por entendermos que se trata de um conteúdo científico normalmente explorado em livros didáticos de ciências e por ter sido localizado em edição recente da revista Ciência Hoje das Crianças (CHC). Esta revista consiste em conceituado material de divulgação científica, sendo distribuído para escolas da rede pública de ensino. O texto didático selecionado compõe o livro "Ciências Naturais: aprendendo com o cotidiano", de Eduardo Leite do Canto, aprovado na última edição do PNLD (Programa Nacional do Livro Didático) das séries finais do ensino fundamental $^{2}$.

O corpus bruto foi delimitado com base em critérios distintos para cada gênero textual: no livro didático foi selecionada apenas a seção "Exemplo de atuação hormonal: a adrenalina", que falava especificamente do hormônio adrenalina, apesar do mesmo ser mencionado em outras partes do capítulo (como na introdução e nos exercícios). Na revista CHC a unidade de análise ficou restrita ao próprio texto sobre a adrenalina intitulado "Adrenalina, a mensageira das fortes emoções", de autoria de Uberdan Guilherme Mendes de Castro ${ }^{3}$.

\section{2 $2^{\mathrm{a}}$ etapa: Descrição do corpus}

Na etapa descritiva focalizamos o como se diz, quem diz e em que circunstância é dito. Para tanto, iniciamos com uma caracterização geral de cada um dos textos buscando compreender as circunstâncias da enunciação dos discursos, bem como transformar o corpus bruto em objeto discursivo.

O texto didático "Exemplo de atuação hormonal: a adrenalina" está inserido no capítulo 7 do livro, intitulado "Sistema Endócrino". A adrenalina é mencionada na página de abertura do capítulo, ao lado de uma imagem de pessoas em um carrinho de montanha russa de um parque de diversões. As seções que antecedem à nossa unidade de análise tratam das funções do sistema endócrino no corpo humano, sua atuação via produção hormonal, os tipos de glândulas especializadas na produção dos hormônios e a localização anatômica dos órgãos que compõem o sistema endócrino. A adrenalina aparece em duas subseções: "Adrenalina é liberada ao levarmos um susto" e "A duração dos efeitos hormonais é variável". Na primeira, o autor dá como exemplo de susto o latido inesperado de um cachorro e, a partir dele, constrói uma explicação sobre a ação da adrenalina no corpo humano. Na segunda subseção, ainda utilizando o exemplo do susto, o autor contrapõe a duração da ação da adrenalina e do

\footnotetext{
${ }^{1}$ CANTO, Eduardo L. Ciências Naturais: aprendendo com o cotidiano. $8^{\circ}$ ano. 3. ed. São Paulo: Moderna, 2009.

${ }^{2}$ Guia do PNLD 2011 disponível em http://www.fnde.gov.br/programas/livro-didatico/guia-do-livro/item/2349guia-pnld-2011-\%E2\%80\%93-anos-finais-do-ensino-fundamental.

3 CASTRO, Uberdan Guilherme M. de. Adrenalina, a mensageira das fortes emoções. Ciência Hoje das Crianças, ano 26, n. 243, março 2013.
} 
hormônio de crescimento no corpo humano. Ambas as subseções estão em uma única página que possui duas fotos: outra foto de pessoas em uma montanha russa e uma foto de um homem com gigantismo.

O texto de divulgação científica (TDC) "Adrenalina, a mensageira das fortes emoções" ocupa duas páginas da revista e tem uma única imagem, um desenho de um cachorro correndo atrás de um menino. Pela ilustração, a leitura do lide da reportagem e o texto introdutório, há o contexto de criação da explicação da ação da adrenalina no corpo humano, que é o mesmo daquele utilizado no texto didático: o contato inesperado com um cachorro que late e provoca o susto. O texto se subdivide em três seções: "Atenção... Ação!”, "Mensagem para você" e "Efeito prolongado". Na primeira, o autor dá a localização da glândula produtora da adrenalina e comenta como sua produção é "ativada". Na segunda, ele explica o mecanismo de ação da adrenalina em diferentes partes do corpo humano em situações de "perigo". Na última seção, ele discorre sobre o efeito da adrenalina no organismo após sua liberação. Existe ainda um quadro em destaque - "Susto animal" - no qual é dito que a adrenalina também é responsável pelos bichos reagirem "às ameaças de uma forma bem parecida com a nossa”.

Entendemos, a partir de nosso dispositivo teórico, que aquilo que é dito pelo sujeito (conteúdo do discurso) e como ele diz (forma do discurso) tem relação direta com sua posição enunciativa. Esta é determinada pelo lugar social que ele ocupa no momento da enunciação e sua relação com o conteúdo do discurso. Além disso, as imagens que ele possui de seu interlocutor determinam a forma como ele seleciona e constrói os argumentos presentes em seu texto. No texto didático, o autor é licenciado em química, doutor em Ciências e com experiência na autoria de livros didáticos e paradidáticos. Trata-se, portanto, de alguém "autorizado" tanto do ponto de vista científico quanto pedagógico para falar do corpo humano e seus sistemas no contexto do ensino formal. Aqui, ele possui o objetivo específico de ensinar conteúdos científicos, já que seu texto circulará em aulas nas escolas e não em outro espaço qualquer. Portanto, mesmo que haja uma tentativa de aproximação com o cotidiano do aluno (seu principal interlocutor) ele não pode/deve afastar-se de seu objetivo central e da formalidade que dele decorre. Por isso, o discurso científico sobressai-se frente ao discurso cotidiano. O excerto abaixo ilustra essa marca discursiva do texto do livro didático (LD).

\footnotetext{
Vamos supor que você esteja andando distraidamente pela rua e, ao passar em frente ao portão de uma casa, um enorme cachorro avance latindo em sua direção. Muito antes de perceber que entre você e ele existe um portão fechado e que o animal não conseguirá feri-lo, seu corpo exibe uma série de sinais decorrentes da descarga de adrenalina no sangue. Sob efeito da adrenalina, hormônio produzido pelas glândulas adrenais, o coração bate mais rápido, o ritmo respiratório aumenta, as contrações dos músculos ficam mais potentes e o corpo fica menos sensível ao cansaço [LD, grifos do autor].
} 
Destacamos que o pronome de tratamento "você" ainda não tinha sido utilizado pelo autor em todo o capítulo até chegar nessa passagem, e depois de estabelecida a conexão com uma situação cotidiana do aluno, o autor retoma o discurso formal (e autoritário) da Ciência com nomeações de entidades científicas e explicações de processos fisiológicos.

No texto de divulgação científica, o autor é apresentado como integrante do Laboratório de Hipertensão, da Universidade Federal de Ouro Preto. Sua titulação e função não são informadas. Porém, como alguém que trabalha em um laboratório científico, ele também estaria autorizado a falar sobre assuntos científicos. O texto deste autor, por ter sido publicado na revista $\mathrm{CHC}$, apresenta características textuais específicas, já que o público leitor consiste em crianças e adolescentes essencialmente frequentadores de escolas. Não podemos, no entanto, deixar de mencionar que em ambos os textos existe outro interlocutor fundamental: o professor. É ele que geralmente tem o primeiro contato com o texto, seleciona-o e media sua inserção na sala de aula. Porém, o professor também tem como interlocutor último o aluno.

Retomando o texto de divulgação científica, percebemos que o contexto inicial para a criação da explicação do processo científico é semelhante àquele presente no livro didático. Há também uma aproximação ao cotidiano do leitor, mas notamos que o autor preocupa-se em dar outros exemplos e acaba dedicando mais espaço a essa parte introdutória (que inclui o lide e dois parágrafos do texto em si) do que àquela presente no texto didático.

Todo mundo já passou por uma situação assustadora: pode não ter sido com o cachorro do vizinho, e, sim, com aquele filme de terror, ou com um amigo que, de brincadeira, se escondeu atrás do sofá e deu um grito logo que você entrou na sala. Quando essas coisas acontecem, a reação normal é... Sentir medo, ué! Ninguém é de ferro! (...) Ao sinal de que algo não vai bem, é como se todos os nossos órgãos trabalhassem para arrumar um jeito de escapar daquela enrascada. Para que isso dê certo, porém, é fundamental que nosso cérebro se comunique rapidamente com os órgãos, mandando sinais sobre o que cada um deve fazer. A responsável por tudo isso é a adrenalina, uma substância mensageira de fortes emoções! [TDC]

No texto da revista, o conteúdo parece estar mais "diluído", embora termos científicos sejam utilizados e, em alguns períodos, haja alta densidade conceitual. Notamos que os processos explicativos são construídos de modos distintos nos dois textos e que até mesmo algumas nomeações científicas diferem neles ("glândulas adrenais" no texto didático e "glândula supra-renal" no texto de divulgação). Encontramos, ainda, a presença de uma marca textual importante no texto de divulgação científica, que é o uso de analogias, conforme exemplificado no trecho abaixo.

Quando tudo está calmo, a adrenalina fica concentrada, principalmente, em um pequeno órgão chamado glândula supra-renal, que recebe esse nome por 
estar localizado bem em cima dos rins. Porém, quando pressentimos um perigo, a adrenalina sai do esconderijo, entra no sangue e chega a vários outros órgãos. [TDC]

Em ambos os textos notamos a construção da explicação a partir da mobilização de argumentos que atribuem à ação da adrenalina uma relação de causa-efeito, envolvida em processos fisiológicos que relacionam um órgão a uma função específica que, apesar de em alguns casos ser involuntária, assume um caráter de "auto-consciência". Essa característica é típica do discurso escolar sobre a ciência e que, apesar de sofrer fortes críticas por pesquisadores em educação em ciências, permanece no tex to do livro didático e também pode ser encontrado no texto de divulgação. Os excertos abaixo ilustram essa propriedade discursiva.

Sob efeito da adrenalina, hormônio produzido pelas glândulas adrenais, o coração bate mais rápido, o ritmo respiratório aumenta, as contrações dos músculos ficam mais potentes e o corpo fica menos sensível ao cansaço. Isso é uma preparação para uma resposta rápida e intensa como fugir ou brigar. O fluxo de sangue para os intestinos e para a bexiga urinária é reduzido, pois atividades como digestão e excreção podem esperar até que o perigo passe. [LD, grifos do autor]

Para perceber uma ameaça, nosso corpo pode usar a visão (olhar o cachorro em posição de ataque, por exemplo), a audição (o barulho de uma explosão) e outros sentidos. Cada um deles é capaz de ativar uma região do cérebro chamada sistema límbico, que atua no controle das emoções, da memória e do aprendizado. É ele que emite o sinal de alerta para que a adrenalina saia das glândulas supra-renais e comece a viajar pelo corpo. [TDC]

Apesar dos dois textos tratarem do mesmo tema situado no âmbito da Ciência e, supostamente, o discurso científico ser constitutivamente autoritário e parafrásico, encontramos algumas passagens em "discordância" que pode levar a deslocamentos e produzir diferentes efeitos de sentidos.

\footnotetext{
Alguns minutos depois, o susto terá passado. Cessados os efeitos da adrenalina, tudo voltará ao normal: a pulsação, a respiração, a cor da pele etc. Esse é um exemplo de atuação hormonal que dura poucos minutos. [LD]

Muitas vezes o efeito da adrenalina sobre os órgãos demora a passar. Se o susto foi grande, você pode continuar sentindo o coração acelerado vários minutos depois, ou mesmo sentir as mãos tremendo ainda que você esteja em um lugar totalmente seguro. [TDC]
} 


\section{$4.33^{\text {a }}$ etapa: Interpretação do objeto discursivo}

$\mathrm{Na}$ etapa interpretativa do objeto discursivo retomamos aspectos textuais destacados na descrição do corpus e, assim, passamos à compreensão das condições de produção e da interdiscursividade que caracterizam as formações discursivas "livro didático" e "revista de divulgação científica". Para tanto, partimos das marcas textuais que nos remetem às relações de sentidos, às relações de força e ao mecanismo de antecipação.

Quando adentramos o universo discursivo dos textos analisados encontramos o espaço da intertextualidade, que permite que aquela formação discursiva específica se constitua a partir do estabelecimento de relações de sentidos. No texto didático, ao mesmo tempo em que encontramos o discurso cotidiano por meio do estabelecimento do diálogo do autor com o leitor a partir de uma situação possivelmente já vivenciada (ou conhecida) por este (afinal, não é em qualquer bairro ou cidade que existe um parque de diversões com uma montanha russa), percebemos a forte presença do discurso científico. Outro discurso que também se faz presente é o discurso pedagógico na medida em que o autor pressupõe que a leitura daquele texto não teve início naquela seção sobre a adrenalina. Logo, o leitor (aluno) já teria aprendido sobre o que é uma glândula, o que ela produz e suas funções. Além disso, ele também já saberia o que é o movimento respiratório e a contração muscular. Esse encadeamento de conteúdos típicos do discurso pedagógico consiste em outro atravessamento presente no texto didático. É interessante notar que é no estabelecimento dessa interdiscursividade que se constrói o discurso científico escolar que está materializado no texto do livro didático de ciências. Já no texto de divulgação científica, o discurso cotidiano está mais presente e os exemplos selecionados pelo autor podem parecer mais familiares ao leitor. Por outro lado, o discurso científico é valorizado quando as explicações sobre a fisiologia humana estão centradas em conceitos e processos construídos e interpretados no âmbito da Ciência. Por não estar diretamente relacionado a uma esfera de ensino formal, o autor do texto de divulgação acaba sendo mais criterioso na construção de suas explicações, pois seu público é mais heterogêneo (nem todos estão na mesma série escolar ou estudaram o corpo humano) e, por isso, acaba sendo visto como "genérico". Ao fazê-lo, o autor lança mão de recursos típicos do discurso pedagógico (didático) como o uso de analogias (metáforas) as quais “cumprem, principalmente, a função de 'traduzir' os conceitos científicos em linguagem comum" (BRAGA e MORTIMER, 2003, p. 62). A formação discursiva divulgação científica é, portanto, caracterizada pelas relações de sentido estabelecidas por esses discursos que atravessam seu texto.

A autoridade que o discurso científico delega àquele que não apenas o detém, mas que se propõe a escrever sobre ele, gera uma diferença de status entre o autor e o leitor. Porém, as imagens que o autor tem deste leitor, bem como a circunstância imediata de enunciação, fazem com que o primeiro busque se aproximar do segundo, diminuindo a distância entre eles, de modo a inclui-lo em seu discurso. Essas relações de força influenciam na própria organização textual e na construção da necessidade pela explicação científica, e são observadas nos dois textos quando seus autores recorrem a experiências cotidianas do leitor para produzirem seus discursos. Nesse sentido, o lugar social que o autor ocupa no ato enunciativo é mantido e, ao mesmo tempo, deslocado por conta do dialogismo intrínseco a 
qualquer discurso.

Essa propriedade do discurso está intimamente relacionada à seleção das palavras e à elaboração dos argumentos que o autor realiza em função daquilo que ele imagina que surtirá como efeitos de sentidos de seu texto. Ao colocar-se no lugar do leitor, o autor do texto didático pressupõe que o leitor/aluno já saiba o que é o sistema endócrino e, portanto, limitase a explicar a atuação do hormônio adrenalina no corpo humano. Por outro lado, devido ao mecanismo de antecipação e das próprias condições de produção do discurso, o autor do texto de divulgação científica constrói uma explicação argumentativa que envolve a mobilização de outros conceitos científicos (por exemplo, a localização e as funções desempenhadas pelo sistema límbico), o que sinaliza aquilo que ele considera como efeito de seu discurso sobre seu interlocutor.

\section{Considerações Finais}

O presente trabalho insere-se na linha de pesquisa da área de Educação em Ciências, que tem nos estudos do discurso seu referencial teórico-metodológico para a investigação de diferentes objetos de estudo. Aqui, particularmente, olhamos para discursos de textos escritos relacionados à Ciência e propomos um dispositivo analítico baseado na Análise de Discurso francesa buscando a caracterização dos mesmos. Selecionamos dois textos inscritos em diferentes formações discursivas (livro didático de ciências e revista de divulgação científica) e, a partir de três etapas de análise (seleção do corpus, descrição do corpus e interpretação do objeto discursivo), promovemos um exercício no qual explicitamos algumas de suas marcas textuais, buscando relacioná-las aos constructos teóricos de condições de produção e interdiscursividade.

De uma forma geral, observamos no texto do livro didático que seu discurso é atravessado por diferentes formações discursivas: ciência, cotidiano, ensino de ciências. No texto de divulgação científica, apesar do ensino formal de ciências não se constituir como condição de produção do discurso, ele parece atravessá-lo, mas enquanto um discurso pedagógico que permite o autor organizar seus argumentos, construir suas explicações e utilizar figuras de linguagem como as analogias. O cotidiano serve como contexto inicial para apresentação da explicação científica propriamente dita. No entanto, o próprio discurso científico parece ser recontextualizado de forma distinta daquela que é feita no texto didático. Essa propriedade discursiva pode ser atribuída não apenas aos diferentes suportes, gêneros textuais, mas às próprias condições enunciativas (quem diz, para quem diz, com qual objetivo e em que circunstâncias). Nesse sentido, explicitamos algumas relações de força e de sentidos que são estabelecidas entre os interlocutores em cada um dos textos.

Entendemos, assim como Orlandi (2002), que ao término de uma análise o objeto permanece aberto para novas abordagens "e isto não tem a ver com a objetividade da análise mas com o fato de que todo discurso é parte de um processo discursivo mais amplo que recortamos e a forma do recorte determina o modo de análise" (p. 64). Desta forma, o dispositivo analítico que foi utilizado no estudo empreendido neste artigo consiste apenas em 
uma das possíveis formas de análise do corpus selecionado e seus resultados podem ser corroborados ou refutados por outras pesquisas de acordo com os objetivos e as questões postas pelo analista do discurso. Esperamos, por outro lado, ter contribuído para o desenvolvimento de uma ferramenta analítica de textos escritos relacionados à Ciência que tem na Análise de Discurso seus pressupostos teóricos.

\section{Referências}

ALMEIDA, M. J. P. M. et al. Leitura e escrita em aulas de ciências: luz, calor e fotossíntese nas mediações escolares. Florianópolis: Letras Contemporâneras, 2008.

ALMEIDA, M. J. P. M. et al. Condições de produção no funcionamento da leitura na educação em física. Revista Brasileira de Pesquisa em Educação em Ciências, v. 1, n. 1, p. 1-13, 2001. Disponível em: <http://revistas.if.usp.br/rbpec/article/view/212/196>. Acesso em 8 ago. 2013.

ANDRADE, I. B.; MARTINS, Isabel. Discursos de professores de ciências sobre leitura. Investigações em Ensino de Ciências, v. 11, n. 2, p. 121-151, 2006. Disponível em: <http://www.if.ufrgs.br/ienci/artigos/Artigo_ID148/v11_n2_a2006.pdf>. Acesso em 19 ago. 2007.

BRAGA, S. A. M.; MORTIMER, E. F. Os gêneros de discurso do texto de biologia dos livros didáticos de ciências. Revista Brasileira de Pesquisa em Educação em Ciências, v. 3, n. 3, p. 56-74, 2003. Disponível em: <http://revistas.if.usp.br/rbpec/article/view/150/135>. Acesso em 25 fev. 2004.

CASSIANI DE SOUZA, S. Condições de produção de sentidos em textos didáticos. Ensaio Pesquisa em Educação em Ciências, v. 8, n. 1, p. 1-14, 2006. Disponível em:

$<$ http://www.portal.fae.ufmg.br/seer/index.php/ensaio/article/view/108/159>. Acesso em 13 abr. 2007.

CASSIANI DE SOUZA, S.; GALIETA-NASCIMENTO, T. Um diálogo com as histórias de leituras de futuros professores de ciências. Pro-Posições, v. 17, n. 1(49), p. 105-136, 2006. Disponível em:

<http://www.proposicoes.fe.unicamp.br/ proposicoes/textos/49_dossie_souzasc_etal.pdf>. Acesso em 15 set. 2012.

FERREIRA, M. C. L. O quadro atual da Análise de Discurso no Brasil. Revista Letras, n. 27, p. 39-46, jul-dez, 2003. Disponível em:

<http://w3.ufsm.br/revistaletras/artigos_r27/revista27_3.pdf>. Acesso em 8 ago. 2013.

GALIETA-NASCIMENTO, T. Contribuições da análise do discurso e da epistemologia de Fleck para a compreensão da divulgação científica e sua introdução em aulas de ciências. 
Ensaio - Pesquisa em Educação em Ciências, v. 7, n. 2, p. 1-18, 2005. Disponível em: <http://www.portal.fae.ufmg.br/seer/index.php/ensaio/article/viewFile/95/143>. Acesso em 10 mar. 2006.

GIRALDI, P. M. Leitura, escrita e educação em ciências: um diálogo com professores de ciências. In: GALIETA-NASCIMENTO, T. (Org.). Ensino de ciências em Programas de Pós-Graduação no Brasil: tendências de pesquisa. Curitiba, PR: CRV, 2012.

O dito e o não dito sobre transgênicos em livros didáticos de biologia. In:

MORTIMER, E. F. (Org.). In: ENCONTRO NACIONAL DE PESQUISA EM EDUCAÇÃO EM CIÊNCIAS, 6., 2007. Anais... Florianópolis: ABRAPEC, 2007, p, 1-12. Disponível em: <http://www.nutes.ufrj.br/abrapec/vienpec/CR2/p1074.pdf>. Acesso em 8 ago. 2013.

LIMA, M. E. C. de C. et al. Formação de conceitos científicos: reflexões a partir da produção de livros didáticos. Ciência \& Educação, v. 17, n. 4, p. 855-871, 2011. Disponível em: <http://www.scielo.br/pdf/ciedu/v17n4/a06v17n4.pdf>. Acesso em 14 ago. 2012.

MARTINS, E. Livro didático: discurso científico ou religioso. Dissertação (Mestrado em Ciências da Linguagem). Universidade do Sul de Santa Catarina, Palhoça, SC: UNISUL, 2006.

MOREIRA, M. C. do A. O discurso da pesquisa em educação em ciências recontextualizado no livro didático de ciências. In: MARTINS, I. et al. (Orgs.). O livro didático de ciências: contextos de exigência, critérios de seleção, práticas de leitura e uso em sala de aula. Rio de Janeiro: [s.n.], 2012.

NICOLLI, A. A.; CASSIANI, S. Das histórias de leitura e escrita às práticas docentes de leitura e escrita de futuros professores de ciências. Alexandria - Revista de Educação em Ciência e Tecnologia, v. 5, n. 2, p. 69-81, 2012. Disponível em: <http://alexandria.ppgect.ufsc.br/files/2012/09/aline.pdf>. Acesso em 8 ago. 2013.

NICOLLI, A. A.; OLIVEIRA, O. B. de; CASSIANI, S. A linguagem na Educação em Ciências: um mapeamento das publicações dos ENPECs de 2005 a 2009. In: ENCONTRO NACIONAL DE PESQUISA EM EDUCAÇÃO EM CIÊNCIAS, 8., 2007. Atas... Campinas, SP: ABRAPEC, 2011. p. 1-14 Disponível em:

<http://www.nutes.ufrj.br/abrapec/viiienpec/resumos/R0304-2.pdf>. Acesso em 8 ago. 2013. ORLANDI, E. P. Michel Pêcheux e a Análise de Discurso. Estudos da Língua(gem), n. 1, p. 9-13, jun. 2005. Disponível em:

<http://www.cpelin.org/estudosdalinguagem/n1jun2005/artigos/orlandi.pdf >. Acesso em 21 abr. 2007.

Análise de discurso: princípios e procedimentos. 4. ed. Campinas, SP: Pontes, 2002.

Discurso e leitura. 2. ed. São Paulo: Cortez, 1993. 
A linguagem e seu funcionamento: as formas do discurso. São Paulo: Editora Brasiliense, 1983.

PÊCHEUX, M. O discurso: estrutura ou acontecimento. Campinas, SP: Pontes, 1990.

PEREIRA, A. G.; TERRAZAN, E. A. A multimodalidade em textos de popularização científica: contribuições para o ensino de ciências para crianças. Ciência \& Educação, v. 17, n. 2, p. 489-503, 2011. Disponível em:

<http://www.scielo.br/pdf/ciedu/v17n2/a15v17n2.pdf>. Acesso em 8 ago. 2013.

PINHÃO, F. L.; MARTINS, I. O discurso sobre saúde e ambiente no livro didático de ciências brasileiro. Revista Electrónica de Enseñanza de las Ciencias, v. 11, n. 2, p. 342364, 2012. Disponível em:

<http://reec.uvigo.es/volumenes/volumen11/REEC_11_2_5_ex595.pdf>. Acesso em 10 out. 2012.

A análise do discurso e a pesquisa em ensino de ciências no Brasil: um levantamento da produção em periódicos entre 1998 e 2008. In: ENCONTRO NACIONAL DE PESQUISA EM EDUCAÇÃO EM CIÊNCIAS, 7., 2009. Atas... Florianópolis: ABRAPEC, 2009. p. 1-12 Disponível em: <http://posgrad.fae.ufmg.br/posgrad/viienpec/pdfs/518.pdf>. Acesso em 8 ago. 2013.

SILVA, H. C.; ALMEIDA, M. J. P. M. O deslocamento de aspectos do funcionamento do discurso pedagógico pela leitura de textos de divulgação científica em aulas de física. Revista Electrónica de Enseñanza de las Ciencias, v. 4, n. 3, p. 1-25, 2005. Disponível em: <http://reec.uvigo.es/volumenes/volumen4/ART8_Vol4_N3.pdf>. Acesso em 16 set. 2007.

SOUZA, G. dos S. M.; SILVA, E. S. da; SANTOS, K. N. dos; SANTOS, B. F. dos. A pesquisa sobre linguagem e ensino de ciências no Brasil em teses e dissertações (2000-2011). In: GALIETA, T.; GIRALDI, P. M. (Orgs.). Linguagens e Discursos na Educação em Ciências. Rio de Janeiro: Multifoco, 2014.

Recebido em: 02/03/2014

Aprovado para publicação em: 24/02/2016

Publicado em: 31/08/2016 